\title{
CCG-0922 APL Regimen
}

National Cancer Institute

\section{Source}

National Cancer Institute. CCG-0922 APL Regimen. NCI Thesaurus. Code C67482.

A regimen consisting of idarubicin, administered with continuous infusion fludarabine, followed by a continuous infusion of cytarabine and used for the treatment of relapsed or refractory, childhood acute myeloid leukemia (AML). 